\title{
Devasa Çok Oyunculu Çevrimiçi Oyunlarda Ürün Yerleştirme: Bir İçerik Analizi
}

- Süleyman KARAÇOR Prof.Dr. Selçuk Üniversitesi skaracor@selcuk.edu.tr ORCID ID: 0000-0002-31460232

- Muammer ÖZTÜRK Doktorant (YÖK 100/2000) Selçuk Üniversitesi muammer@live.com ORCID ID: 0000-0001-81247096

\section{ÖZET}

Teknolojinin sürekli gelişmesinin sonucu olarak yeni reklam alanlarının da ortaya çıktığ görülmektedir. İlk yıllarında sinemada ortaya çıkan ürün yerleștirme, televizyon dizileri, müzik klipleri ve yarışma programlarl, radyo yayınları ve kitap dergi gibi bastl yayınlarla sinırlı kalmıştır. Günümüzde ise ürün yerleştirme uygulamalar sosyal ăg sitelerinde yeni medyanın tamaminda, internet tabanl oyunlar ve akull telefon uygulamalarında yerini almıştır. Bunların yanı sıra dinamik ve popüler bir alan olan çevrimiçi oyunlarda ürün yerleştirmede aktif olarak kullanılmaktadır. Dijital oyun dünyası geniş çapta hedef kitleye hitap ettiği için her yaş düzeyine uygun oyunlar bulunmaktadır. Cevrimiçi sistemler aracılığılyla üyelikle katılmaya imkan veren bu dijital oyunların hedef kitleyi belirlemede kolaylık sağlamalarıyla markaları başarıya ulaştırdığıbilinmektedir. Piyasada bir çok farklı temada oyun yer alırken, bu oyunların konusuna uygun ürünün yerleștirilmesi oyuncular tarafindan fark edilmesi daha kolay hale geleceğinden bu konuya dikkat edilmesi gerekmektedir. Bu araştırmada ilk Türk yapımı ve ücretsiz olan devasa çok oyunculu çevrimiçi oynanan ZULA'da yerleştirilmiş ürünler içerik analizi tekniğiyle ele alınmiştır. Araştırmada edinilen bulgulara göre oyun içerisinde, glda, otomotiv, teknoloji başta olmak üzere farkl sektörlerden ürün ve hizmet veren markaların ürün yerleştirmeleri tespit edilmiştir.

Anahtar Sözcükler: Ürün yerleștirme, çevrimiçi oyunlar, çok oyunculu oyunlar, oyun çeşitleri, oyun tarihi 


\section{Product Placement In Massively Multiplayer Online Games: A Content Analysis}

- Süleyman

KARAÇOR

Prof. Selcuk University

skaracor@selcuk.edu.tr

ORCID ID: 0000-0002-31460232

\section{- Muammer ÖZTÜRK}

$\mathrm{PhD}$ candidate (CoHE

100/2000) Selcuk University muammer@live.com ORCID ID: 0000-0001-81247096

\begin{abstract}
As a result of the continuous development of technology, it is seen that new advertising spaces have emerged. The product placement that emerged in the cinema in its early years was limited to television series, music videos and print publications such as competition programs, radio broadcasts and book magazines. Today, product placement applications have taken place in all of the new media on social network sites, internet-based games and smart phone applications. In addition to these, it is actively used for product placement in online games, which is a dynamic and popular field. Since the digital game world appeals to a wide range of target audiences, there are games suitable for all ages. It is known that these digital games, which allow participation with membership through online systems, make brands successful by providing convenience in determining the target audience. While there are games in many different themes in the market, it is necessary to pay attention to this issue as the placement of the product suitable for the subject of these games will become easier for the players to notice. In this research, the products placed in ZULA, which is the first Turkish made and free massive multiplayer online game, were handled with content analysis. According to the findings of the research, product placements of brands that provide products and services from different sectors, especially food, automotive and technology, were determined in the game.
\end{abstract}

Keywords: Product placement, online games, multiplayer games, game types, game history 


\section{GİRIŞ}

Çağımızın çekişmeli rekabet piyasası, hedef kitlenin reklam mesajlarına maruz kalma sıklıklarının sürekli artış göstermesi ve hayatımızın her köşesinin reklam içerikleriyle donatılmasına sebebiyet vermektedir. Markaların tüketicilere ulaşma ve etkilemede yeni yöntemler keşfinde büyük uğraşlar sergiledikleri bu dönemde ürün yerleştirme, etkin bir pazarlama iletişimi aracı olarak ön plana çıkmaktadır.

Filmlerin başarılar elde etmesiyle sinema insanlık tarihindeki en önemli kitle iletişim araçlarından biri haline gelmiştir.Sinemanın izleyiciler tarafından aşırı talep görmesiyle reklamcılarında ilgisini çekmiştir.Bununla birlikte ilk ürün yerleştirme uygulamaları sinemada başlayarak tüm kitle iletişim araçları dahil olmak üzere hayatımızın her alanında görebilmemiz mümkündür. Bilişim sektörünün hız kesmeyen ilerleyişi de her geçen gün reklamcılar için yeni mecralar yaratmaktadır.

Reklamlar, kitle iletişim araçlarının hayatını sürdürdüğü teknolojik gelişmelere eş zamanlı olarak oldukça etkili ve değişik mecralarda varlığını hissettirmeye başlamışlardır. Günümüzde medya planlamaları tasarlanırken klasik anlayıştan uzaklaşarak ve reklam iletilerinin hedef kitlelere ulaştırmada güncel yaklaşımlar sergilemektedirler. Geleneksel medya, yapımların içine yoğun reklam iletileri barındırdığı için izleyicinin reklamdan uzaklaşmasına neden olmaktadır. Bu yüzden reklamcılar tüketicilere marka ile ilgili mesajları sunmak için çeşitli çözümler aramaktadırlar (Vaerenbergh, Sompel, Loock, \& Vermeir, 2011, s. 21)

Ürün yerleştirme esasında bir reklam çeşidi olarak bilinsede geleneksel reklamlarla arasında ciddi farklılıklar bulunmaktadır. Ürün yerleştirme uygulamalarının tüketiciyi ikna etme özelliği geleneksel reklamlara göre daha az fark edilir biçimdedir (Chan, Lowe, \& Petrovici, 2016, s. 35). Ürün yerleştirme uygulamaları, hedef kitlenin yayın akışına odaklanmış halde kalmasına imkan vermekte ve bunu sağlarken bir takım ilham verici duygular kullanmaktadır. Bu duygular, markayı istenilen mesajları izleyiciyle buluşturmanın bir aracı olarak kullanan reklam yazarları, yayındirektörleri ve diğer kreatif profesyoneller tarafından oluşturulmaktadır (Liang, Hsiao, \& Cheng, 2015, s. 1213). Kısaca ürün yerleştirme, reklam ile eğlenceyi bir araya getirirek markanın hedef kitlenin zihninde yer alma çalışmalarına alternatif çözümlerden biri olmaktadır (Eagle \& Dahl, 2018, s. 605). 
Ürün yerleştirmenin ilk olarak ne zaman uygulanmaya konulduğu ve ilk örneklerinin ne olduğu konusunda farklı görüşler belirtilmektedir. Çoğunluklakabul gören görüşe göre, ücret karşılığ1 yapılan ürün yerleştirme uygulamalarının ilk örnekleri 1920'lerdeki Hollywood filmleri olarak gösterilmektedir. 1920'lerde sigara şirketleri izleyicilerde alg1 oluşturmak amacıyla Hollywood'u etki altına alma faaliyetlerine başlamıştır. Bu etki aracalığıyla filmlerde oynayan oyuncular sigara kullanmaya başlamışlardır. Alkol ve tütün markası sahipleri, Hollywood film yıldızlarına, ürünlerini ekran karşısındaki izleyecilere açıkca göstermeleri ve bu ürünleri severek kullandıklarını söylemeleri karşılığında ödemeler yaparak ürün yerleştirme kavramının temellerini atmışlardır (Balasubramanian, 1994, s. 33).

1934 yılında gösterimde olan 'It Happened One Night' filminde, oyunculardan C. Cable'ın gömleğinin içine iç çamaşırı giymemiş olmasından dolayı bu ürünlerin satış oranları aşırı derece azalarak bu sinemada tesadüfi ve markasız olarak uygulanan ilk ürün yerleştirme örneği olarak kayıtlarda yer almıştır. Bununla birlikte 1951 tarihli 'African Queen’ filminde H. Bogart isimli oyuncunuın Gordon's marka alkol içmesi ve bu sahnenin izleyicilere açıkça gösterilmesi bilinen ilk profesyonel ürün yerleştirme örnekleri arasında yer almaktadır. Bunlara ek olarak; Steven Spielberg isimli aktörün "E.T" filminde dolapta gizlenen yaratığı dışarıya çıkarmak için Hershey markasına ait Reese's Pieces çikolatalı drajesini kullanılmasıda film içinde ürün yerleştirmenin ilklerinden sayılmaktadır. Markanın bu ürün yerleştirmesinden sonra satışları \%66 artmıştır (Tığgl, 2004, s. 33-34).

Sinemanın yanı sıra radyoda da ürün yerleştirme uygulamalarının örnekleri bulunmaktadır. İlk kez 15 dakikalık bir eğlence programı olarak 1939'da dinleyicileriyle buluşmuş "Bing Crosby Chesterfield Show" isimli programda iki çeşit ürün yerleştirme uygulamasının yer aldığı bilinmektedir.Bir sigara markası olan "Chesterfield"'ın programın isminde kullanılmıştır. İkincisi ise programın sunucusu olan "Bing Crosby" yayının başlangıcında sigara markasına ithafen bir şarkı söylemiştir. Chesterfield'ın programın sponsorluğundan ayrılmasıyla yayın General Electric'in firmasının sponsorluğunda aynı düzen ve içerikte devam etmiştir (Zeren \& Paylar, 2014, s. 11-12).

Basılı eserlerde de ürün yerleştirme uygulamaları gerçekleştirilmektedir. Birçok kesim tarafından tanınan mücevher markası Bulgari, yazar Fay Weldon'a kendi ürünlerinin öncelikli olarak içinde geçmesini istediği bir kitap yazması için ücret ödemesi yapmıştır. Fay Weldon'1n kitabı “The Bulgari Connection” diğer yazarlar ve hayranları tarafından farklı 
tepkilere maruz bırakılmıştır. Kitabı tavsiye edenlerkadar bu yaptığının etik olduğunu sorgulayanlar da olsada nihayetinde Weldon, bu eseriyle diğer kitap yazarları ve yayın evlerine de ürün yerleştirme alanında öncülük etmiştir. Kitaplar gibi bir sanat eseri olarak şarkı sözlerinde bir markaya ait ürün adının söylenmeside ürün yerleştirme uygulamalarından biri olarak karşımıza çıkmaktadır. Bu uygulamanın ilk örnekleriden birisi, 1908 yılında Jack Norworth ve Albert Von Tilzer tarafından yazılmış "Take Me Out to the Ball Game" adlı şarkıyı vermek mümkündür. Şarkı sözünün nakarat bölümünde bir aperitif markası olan Cracker Jack'in adı sıç̧a geçmektedir (Neer, 2003).

Ürün yerleştirme uygulamasının sıkça yapıldığı alanlardan biri de video kliplerdir. Bu uygulamanın ortaya çıkışı ilk olarak Sting isimi şarkıcının "Desert Rose” şarkısı için çekilen klibe bir Jaguar marka yerleştirilmesiyle oluşturulmuştur. Bu klipten sonra benzer uygulamalar çoğalmıştır.Örneğin, Celine Dion isimli şarkıcının otomobillerini şarkılarında tanıtması ve reklam filmlerinde yer alması için Chrysler Group, üç yıllığına 14 milyon dolarlık bir anlaşma imzalamıştır. McDonald's markası ise gençler tarafından çok sevilen Justin Timberlake isimli şarkıcı ile markanın o dönemki sloganı olan "I'm lovin'it" şarkısını yazması ve çeşitli konserler ve etkinlikler düzenlemesi için ücret ödemiştir (Akkan, 2006, s. 20).

Reklam amaçlı video oyunlarının kullanımı çok eski zamanlara dayanmaktadır. Budweiser ve Marlboro markalarının Tapper ve Pole Position gibi video oyunlarında yerleştirildiği 80’li yıllar öncesi görülmektedir. Dünya çapında video oyunlarına olan ilginin giderek artması markaların tüketicilere etkili ve dolaylı bir şekilde yaklaşmalarının bir yolu olarak video oyunlarını kullanma ilgilerini de artırmıştır. Video oyunları yalnız genç kuşağa hitap etmemektedir (Martí-Parreñoa, Bermejo-Berros, \& Aldás-Manzano, 2017, s. 55). Oyun kültürü ve geçmişi çok eskilere dayandığından bir çok yaş grubundan insanın oyunlara merakı olduğu bilinmektedir. Çeşitliliği ve erişimi bakımından oyunlar el konsolları, tabletler ve akıllı telefonlar ile mekandan bağımsız oynanma özelliği ile hayatımızın bir parçası haline gelmiştir.

Zeren ve Paylar (2016) tarafindan bir futbol oyunu aracılığıyla bilgisayar oyunlarına yerleştirilmiş olan markaların hatırlanma durumunu, bu markaların farklı hatırlanma derecelerinin olası nedenlerini araştırmak için 179 erkek katılımcıya anket uygulanmıştır. 
Markalara yönelik tutum ve satın alma niyetlerinin farklı nedenlerle birbirlerinden değişkenlik gösterdikleri sonucuna ulaşılmıştır.

Vashisht ve Royne (2016) çalışmasında oyunreklam (advergame) hızının ve ürün yerleştirmenin, tüketici davranışları ve marka hatırlanabilirliği üzerindeki etkisini üniversite öğrencileri üzerinden araştırılmıştır. Düşük hızda olan oyunreklamların, yüksek hızda olanlarına kıyasla daha etkili marka hatırlaması ve belirgin bir ürün yerleştirme ile belirgin olmayan bir ürün yerleştirme arasında marka hatırlama açısından hiçbir fark olmadığını ifade edilmiştir.

Latvasalo (2017) tarafından farklı oyun reklamı entegrasyonlarının marka bilinirliği üzerindeki etkisini test etmek amaciyla bir video oyunu oluşturulmuş ve 291 oyuncuya çevrimiçi anket uygulanmıştır. Daha entegre, etkileşimli ve derin bir oyun reklamcılığı entegrasyonunun, marka hatırlama ve bilinirliği üzerinde daha yüzeysel entegrasyonlara kıyasla iki kat daha fazla etkiye sahip olabileceği belirtilmiştir.

Chaney (2018) araştırmasında bir araba yarışı oyununda önceden seçtikleri dört farklı markanın reklam panoları oyun pistinin içine yerleştirilerek 285 öğrenciyle iki günlük bir deneysel çalışma gerçekleştirmişlerdir. Bunun sonucunda büyük boyutlu reklam panolarının küçük boyutlu reklam panolarına göre daha iyi hatırlandığı tespit edilmiştir.

Çavdar (2020) tarafından yapılan spor oyunlarında ürün yerleştirme çalışmasında dört farklı oyunu incelenerek oyunlar içerisinde toplam 38 farklı sektör ve 187 marka tespit edilmiştir. Bu sektörlerden en fazla sigortacılık - finans ardından otomotiv ve teknoloji gelmekte ve en az yerleştirme yapılan sektörler ise video oyunları, mutfak aletleri, yapı malzemeleri, emlak olarak belirtilmiştir.

Markaların gün geçtikçe ürün yerleştirme faaliyetlerine ağırlık verdiği görülmektedir. Örneğin Apple firması 2010 yılında dünya çapında gişe büyüklüğü en yüksek 33 filmin \%30'unda; Nike, Chevy ve Ford \%24'ünde ve Sony, Dell, Land Rover ve Glock \%15'inde ürün yerleştirme yapıldı̆̆ 1 tespit edilmiştir. Son James Bond filminde toplam film bütçesinin 3/1'ine denk gelen 45 milyon dolar tutarında ürün yerleştirme faaliyeti gerçekleştirilmiştir. PQ Media'nın 2012 verilerine göre dünya genelinde ürün yerleştirmeharcamaları 2011 yılında \%9,8 artarak ve 7,39 milyar dolar seviyesine ulaşmıştır. Dünyanın en geniş ürün yerleştirme pazarına sahip olan sadece Amerika Birleşik 
Devletleri'nde ise 2011 yılında ürün yerleştirme harcamaları \%10,2 artarak 4,26 milyar dolara erişmiştir (Chen \& Wang, 2016, s. 835-836).

Çevrimiçi oyunlar, insanlara çok fazla zaman harcatmakta ve her geçen gün farklı yaştan insanı evrenine dahil etmektedir. Oyun çeşitliliğinin fazla olması bu artışın en büyük etkenidir. Oyun endüstrisinin piyasadaki durumuna bakıldığında çok gelişmiş olduğu ve ilerlemeye devam ettiği göz ardı edilemez. Bu oyunlar, doğası gereği etkileşimli olması ve belirli bir hedef kitleye hızlı erişim sağlamasından dolayı markalar için mükemmel bir reklam mecrası haline gelmiştir. Oyun içinde yapılan ürün yerleştirmelerin sayısı oyunun içeriğine göre değişmekte ve farklı kategorilerde olabilmektedir.

\section{TARİHSEL SÜREÇ İÇERİSINDE OYUN KAVRAMI}

Oyunun tarihsel sürecine bakıldığında, Platon ve Aristoteles'in derinlemesine ele aldığ̣ bir konu olarak görülmektedir.Platon'a göre oyun, bir faaliyet ya da hissin dişa vurulmasında kullanılan araç olarak nitelendirilmektedir. Bunun yanında oyun sadece eğlence faaliyeti biçiminde değil, antik site devleti vatandaşının küçüklügünden başlayıp, etik olan davranışları örnek almasında büyük yarar sağlayan bir araç olduğu bilinmektedir. Platon'un düşüncelerinde şekillendirici rolü bulunan oyun, Aristoteles'in düşüncelerinde bir çeşit deşarj olma ve zihni dinlendirme biçimi olarak, eğlence için ayrılan vaktin yararlı ve yararsız olarak doldurulması biçiminde belirtilmiştir. Aristoteles oyun için bağımsızlık kavramının eylem dönüştürülmüşs şekli olmasını ifade ederek, kişinin çaba harcayıp sonunda kazanmış olduğu bir hediye olarak tanımlamaktadır (Yengin, 2012, s. 90-92). Oyun, hem insan hem de hayvan alemine kadar yayılmış geniş bir alan hitap eden, günlük yaşamın her anında mevcut mazisi çok eskiye dayanan bir eylem olarak ortaya çıkmaktadır (Kanca, 2011, s. 13).

Homo Ludens'i, oyun oynayan insan olarak tanımlayan Johan Huizinga, oyun oynama ediminin ayırt edici özelliklerini şu şekilde açıklamaktadır: “Oyuncu her türlü maddi yarar ve çıkar düşüncesinden, istek ve gereksinimleri karşılamaya yönelik güdüsel mekanizmalardan bağımsızdır; oyuncular, özgürce ve gönüllü olarak onu bir kurmaca biçiminde algılarlar. Her oyun önceden belirlenmiş bir alanın sınırları içinde oynanır ve belirli bir süreyle sınırlıdır; istenildiği kadar yinelenebilir. Bu uzamsal ve süremsel sinırlar, güncel yaşamdan belirli bir süre için koparak, kendine özgü ayrı bir evren -bir oyun evrenikurulabilmesinin somut dayanaklarıdır. Her oyunun kuralları vardır. Bu kurallar çiğnenirse 
oyun evreni de çöker. Oyunbozan, mızıkçı ve düzenbaz, oyunu var kılan "consensus" karşısında ciddi birer tehdit oluştururlar. Oyun alanının içinde özgül ve mutlak bir düzen hüküm sürer. Bu, insanın mükemmellik isteğine her zaman uymayan yaşamın karmaşası içinde, geçici ve sınırları belli bir kusursuzluk arayışıdır. Oyun bir güzellik arayışıdır. Bu estetik faktör, ritim ve harmoniyi her oyunun vazgeçilmez koşulu kılar; oyunun bir diğer temel öğesi olan 'gerilimin'in içerdiği şans ve belirsizliğe düzenli bir biçim verir. Oyun bu özellikleriyle, bayram, tapınç, ritüel, büyü gibi olgularla aynı kutsallık alanını paylaşır; kendine çeker, içine alır, büyüler" (Huizinga, 1995, s. 61-62)

Patenti 1947 senesinde alınmış ilk elektronik oyun, "Cathode Ray Tube Eğlence Cihazı" olarak nitelendirilen bir roket simülatörü olarak bilinmektedir (Tezel, 2016, s. 11). Dijital oyun tarihinde adı geçen ilk etkileşimli elektronik oyun ise Steve Russel'in 1962 senesinde hazırladığı Spacewar oyunudur. Massachusetts Teknoloji Enstitüsünde uzay araştırmaları için hazırlanmış olsa da Spacewar oyununun şimdinin dijital oyun çeşitliliğinin oluşturulmasna liderlik ettiği kabul edilmektedir (Akbulut, 2009, s. 45). Spacewar oyunun ortaya çıkışından yaklaşık 10 yıl sonrasında ise 1971 yılında piyasaya giriş yapan ve günümüzde artık temin edilebilirliğinin kolay olmadığı ticari amaçlı oyunların ilki Computer Space, oyun dünyasının ilerlemesinde bir dönüm noktası olduğu bilinmektedir. Bu oyunun ardından piyasaya sürülen Galaxy Game, Pong, Space Invaders ve Asteroids oyunları, dijital oyunların geçmişinden bahsedilirken kesinlikle kendinden söz ettirecek efsane oyunlar olarak anılmaktadırlar. Özellikle ilk renkli grafiklere sahip dijital Arcade (oyun salonlarında oynanan oyun) oyunu olarak bilinen Pac-Man, günümüzde en çok oynanan oyunlar listesindeki tahtını birakmamaktadır (Terek \& Bat1, 2011, s. 13).

Kişisel bilgisayarlar 1980'li yılların başından itibaren evlerde kullanılmaya başlanmış ve bu bilgisayarlarda mevcut BASIC gibi temel programlama yazılımları sayesinde insanlar sıradan oyunları kendilerine özel kodlayabilme imkanına sahip olmuşlardır.Bu dönemde evlerinde kodladıkları oyunları piyasaya süren firmaların başarı serüvenleride başlamıştır.1982'de temeli atılan Electronic Arts şimdinin bile dünyanın en gelişmiş oyun stüdyolarını elinde tutan büyük bir şirketler grubu halindedir. Dijital oyun dünyasına her geçen gün bir yenisinin eklenmesiyle Simülasyon, Serüven, Spor, Yap-Boz, Platform, Rol Yapma, Taktik, Yarış gibi farklı oyun çeşitleri ortaya çıkmıştır. Zork, Dragon's Lair, PacMan, Donkey Kong, Metroid, Dragon Quest, Metal Gear, Battlezone gibi oyunlar 1980'li 
yıllara adını yazdırmış değerli oyunlar olarak bilinmektedir. Bu yıllarda Commodore, Atari, Sinclair, Apple firmalarının piyasaya sürdüğü bilgisayar ve oyun konsolları sayesinde dijital oyunların ve bilgisayarların artık pahalı bir zevk olmaktan çıkıp herkesin temin edebileceği ürünler haline geldiği dönem olarak anılmıştır. İşlevi sadece oyun oynamaya yönelik Sony PlayStation, Nintendo GameCube gibi konsollar ve kişisel bilgisayar fiyatlarının her bütçeye uygun olmasından dolayı 1990 ve 2000 yılları arasında piyasaya çıkan on binlerce oyunlarla üç boyutlu oyunların ortaya çıkışı bu zaman aralığında internetin hayatımıza girmesiyle kullanıcılar çevrimiçi oyunlar kavramını öğrenmişlerdir. Bu kavramla birlikte sadece çevrimdışı değil, dünyanın herhangi bir yerinden bağlanan kullanıcılara karşı veya parti oluşturarak oyuna girebilme mümkün hale gelmiştir (Usta, 2009).

\section{2.ÇOK OYUNCULU ÇEVRIMIÇI OYUNLAR}

Çok oyunculu çevrimiçi oyunlar, dünya çapında çok sayıda kullanıcının belirli bir sosyal çevreye bağlanması sonucu bilgisayar zekasına karşı tek oyunculu moda alternatif bir seçenek olarak ortaya çıkmıştır.İnternet teknolojilerinin yarattı̆ğ bu yeni olanaklardan yararlanan bu oyunlar, bağlı kullanıcının diğer kullanıcılarla eş zamanlı iletişim kurabilmesi ve birlikte oyun oynayabilmesine imkan tanımasından dolayı tek kişilik oyun seçeneğine göre daha fazla talep görmektedir (Gürcan, Özhan, \& Uslu, 2008, s. 4).

1996'da 3dfx Interactive firmasının ürettiği 3B hızlandırıcı ekran kartı sayesinde bilgisayarların görüntü kalitelerinin performansının artması ve internet hızlarının yükseltilmesiyle beraber çevrimiçi oyun kültürü de gelişim göstererek yirmi yıl öncesinin metin tabanlı sanal gerçeklik oyunları, görsellik kazanarak aksiyon oyunları haline gelmiştir. Bunun sonucu olarak, Warcraft, Knight Online, Metin2 gibi MMORPG (Massively Multiplayer Online Role Playing Game; devasa çok oyunculu çevrimiçi rol yapma oyunları) oyunları giderek popülerlik kazanmıştır.Sanal oyuncu toplulukları, 2000'li yılların başında bilgisayarla rekabet içinde olan oyun konsolu üreticilerinin odağı haline gelmiştir. Playstation (Sony), Game Cube, Wii (Nintendo) ve XBox (Microsoft) gibi şirketler sadece kendi konsollarında oynanabilir oyunlar piyasaya sunarak ve kendi platformlarına özel toplulukların oluşmasına yol açmışlardır (Ömerbaş, 2016). 
Tablo 1: Devasa Çok Kullanıcılı Çevrimiçi Oyun Türleri (Majhi, 2011).

\begin{tabular}{|c|c|c|}
\hline Kisaltma & Tür & Örnek \\
\hline MMORPG & Rol yapma oyunu & Harry Potter \\
\hline MMOFPS & $\begin{array}{l}\text { Birinci şahıs nişanc1 } \\
\text { oyuncu }\end{array}$ & Unreal Tournament \\
\hline MMORTS & $\begin{array}{l}\text { Gerçek zamanli } \\
\text { strateji oyunu }\end{array}$ & Rise of Nations \\
\hline MMODG & Dans etme oyunu & Audition Online \\
\hline MMOMG & $\begin{array}{l}\text { Menajerlik yapma } \\
\text { oyunu }\end{array}$ & The Sims Online \\
\hline MMOR & Yarış oyunu & Drift City \\
\hline MMOCCG & $\begin{array}{l}\text { Kart koleksiyonu } \\
\text { oyunu }\end{array}$ & Astral Tournament \\
\hline MMOSG & Sosyal ağ oyun & Second Life \\
\hline MMOBA & Takım savaşı oyunu & League of Legends \\
\hline
\end{tabular}

Çevrimiçi oyunlarda, oyuncuların mevcut kurallar çerçevesinde ittifak oluşturup ve belirli bir amaca veya düşmana karşı savaşarak iş bölümü içerisinde olmaları sanal dünyadaki oyun kültüründe Michel Maffesolli’nin deyişiyle “yeni bir tür kabileciliğin” ortaya çıkmasına yol açmıştır (Binark \& Bayraktutan-Sütçü, 2008, s. 55). Birçok çeşidi bünyesinde barındıran çevrimiçi oyunlar, din, dil, yaş, kültür, coğrafi sınırlar gibi farklılıklara takılmadan aynı anda çok sayıda oyuncunun bağlanmasıyla başlayan oyunlar olarak tanımlanmaktadır (Topal, 2016, s. 43).

\section{VİDEO OYUNLARINDA ÜRÜN YERLEŞTİRME UYGULAMALARI}

Ürün yerleştirmeyle ilgili çok fazla tanım yapılmış olmakla birlikte bu tanımlar üç ortak özelliğe sahiptirler. Birincisi; ürün yerleştirme uygulamasında gerçekte var olan markaların kullanılıyor olmasıdır. İkincisi; film yapımcılarının, pazarlamacıların yada gerek yapımcıların gerekse pazarlamacıların ürünleri yerleştirmek amacıyla kasıtlı bir faaliyet gerçekleştirmeleridir. Üçüncüsü de ürün yerleştirme uygulamalarının hedef kitle üzerine olan etkisidir. Firmalar ürünlerinin sunmak, hedef kitle üzerinde farkındalık oluşturmak amacıyla ürün yerleştirme yaparken; sinema ve televizyon sektöründe yapımcılar da sahnelere 
gerçeklik oluşturmak amacıyla ürün yerleştirme uygulamaları yapmaktadırlar (Nakıboğlu \& Serin, 2016, s. 137).

Ürün yerleştirme uygulamasının üç tip stratejisi bulunmaktadır.Bu stratejiler; görsel, sözel ve hem sözel hem de görsel ürün yerleştirme stratejileridir (Argan, Velioğlu, \& Argan, 2007, s. 161).

Görsel ürün yerleştirme stratejisi; hedef kitlenin odağını doğrudan ürüne yada markaya yöneltecek sözlü mesaj, işitsel bir etken olmaksızın ürün, marka, logo veya diğer görsel bir öğenin ekrana verilmesidir. Görsel ürün yerleştirme uygulaması bizzat ürünün kendisinin yada ürünün markasının görseli olarak nitelendirilebilir (Mazıcı, Ateş, \& Yıldırım, 2017, s. 242).

İşitsel ve sözel yerleştirme stratejisi; ürünün veya ürüne ait markanın konuşma esnasında geçmesişeklindedir. İşitsel ürün yerleştirme ürünün, markanın gösterildiği duruma göre, söz konusu ifadenin yinelenmesi, kullanılan ses tonuna, konuşmadaki mekan ve ana göre değişiklik göstermektedir (Gerçek \& Tanyıldızı, 2012, s. 1099).

Görsel ve işitsel ürün yerleştirme stratejisi; ürünün ya da markanın olay örgüsünün bir öğesi olduğu, olayda önemli bir yer aldığı ve hatta bir figürün karakteristik özelliklerini oluşturan ürün yerleştirme çeşididir. Görsel ve işitsel ürün yerleştirme uygulamasında, görsel ve işitsel unsurlar kullanılır. Olayın akışı içerisinde ürün hem gösterilir, hem de söz konusu üründen konu edilmektedir (Akıncı \& Çakır, 2014, s. 26).

Yaşadığımız çağın gereği olarak bilgisayarın gün geçtikçe evrim geçirmesi ve yaygınlaşmasıyla birlikte, bilgisayar oyunları artarak çeşitlilik göstermiştir. Kullanıcılara sunulan bilgisayarların yazılım ve donanım özellikleri yükseldikçe bilgisayar oyunları çeşitlenmiş ve gelişmiş, bu sayede de bilgisayar oyunu oynayanların sayısında büyük oranda artış yaşanmıştır. Bilgisayar oyunlarına gösterilen ilginin büyümesiyle beraber oyunlarla yakın olan firma sayısı da artmış, bunun sonucunda da oyunların türleri ve kalitesi artırılarak piyasaya sunulmuştur (Korkusuz \& Karamete, 2013, s. 81). Ürün yerleştirme bilgisayar ortamında izlenen video ya da çeşitli oyunlarda görülebilmektedir.Bir motorlu yarış oyununda virajı alırken pistin herhangi bir yerinde şirket ambleminin görünmesi ya da bir spor müsabakası oyununda saha çevresine reklam panosu olarak yerleştirmesi şeklide uygulanabilir (Altıntaş, 2009, s. 49). 
Video oyunlarında ürün yerleştirme üç farklı yöntemle yapılmaktadır. İlk yöntem, markanın veya ürünün ekranda göründüğ̈ yani görsel ürün yerleştirmeyle yapılan yöntemdir. İkincisi, ses içeriğinin marka veya üründen bahsettiği işitsel ürün yerleştirmedir. Üçüncüsü ise, markanın veya ürünün oyunun alanına tamamen dahil edildiği alan yerleştirmesidir. $\mathrm{Bu}$ yerleştirmeler, ürün yerleştirmenin sinema ve televizyon sektöründe uygulanışı ile birebir aynı şekildedir. Video oyunlarının doğası gereği, video oyunlarında farklı olarak, oyuncu ile marka arasındaki etkileşimin sağlanması yoluyla yapılan yerleştirmeler bulunmaktadır. Oyuncu, oyun içerisinde bir nesne olarak ürünü kullanır bundan ortaya çıkan etkileşim ile ürünün yerleştirilmeye ek bir boyut kazandırır. Bu etkileşim sayesinde de oyuncunun markaya olan farkındalığı artmaktadır (Boluda, Pardo, \& Suemanotham, 2011, s. 5).

\section{METODOLOJI}

\subsection{Amaç}

Araştırmanın amacı, devasa çok oyunculu çevrimiçi video oyunlarında bulunan ürün yerleştirmelerin kategorilerini tespit etmektir. En çok ve en az hangi ürünlerin yerleştirilmesinin yapıldığını ortaya çıkarmak araştırmanın temelini oluşturmaktadır.

Ürün yerleştirmelerin hangi sektörde yer aldıklarını belirlemek amacıyla toplam 14 ayrı sektör (Gıda (İçecek), Otomotiv, Gıda (Yiyecek), Teknoloji, Temizlik, Telekomünikasyon, Giyim, Sinema ve Televizyon, Yap1 Malzemeleri, Sivil Toplum Kuruluşları, Siyasal Reklam, Video Oyunları, Kişisel Bakım, Diğer) baz alınarak Özgen, Yüce, \& Katırcı (2018) tarafından oluşturulankodlama cetveli kullanılmıştır.

\subsection{Yöntem}

Araştırmanın amacına uygun olarak elde edilen verinin incelenmesinde nicel veri toplamatekniklerinden biri olan içerik analizi kullanılmıştır. Bu teknik, özellikle sosyal bilimler alanında çalışma yapan araştırmacılar tarafından uzun yıllardan beri sıklıklatercih edilmektedir. İçerik analizi, yazılı belgeler başta olmak üzere tüm iletişim ortamlarında bulunan bilgilerin ve sembollerin ortaya çıkarılması temeline dayanan sistematik bir veri toplama tekniğidir (Neuman, 2007, s. 67). İçerik analizi, sınırlılıkları belirlenmiş bir ortamdan elde edilen bulgularlaaraştırma problemini çözecek şekilde kategorilendirilmesi, betimlenmesi, veriler içerisindeki belirli değişkenlerin veya kavramlarının ölçülerek anlamlandırılması olarak tanımlanmaktadır (Arık, 1992, s. 119). En genel anlamıyla içerik 
analizine bakıldığında "nitel veriyi nicel veriye dönüştürme yollarından biri” şeklinde ifade edilebilir (Rubin \& Babbie, 2014, s. 452).

\subsection{Evren ve Örneklem}

$\mathrm{Bu}$ çerçevede, ilk Türk yapımı ve ücretsiz olan devasa çok oyunculu çevrimiçi oynanan ZULA amaçlı örnekleme yöntemiyle seçilip Ocak 2019 - Nisan 2019 tarihleri arasındaara verilmeksizin sabah ve akşam saatlerin de düzenli olarak oyun içi gözlemlenmiş ve markaların ürün yerleştirmeleri gruplara ayrılarak incelenmiştir.Amaçlı örneklemenin amacı, araştırmada ele alınacak sorunlarıaçıklığa kavuşturacak zengin bilgi içeren durumları ele almaktır. Bu anlamda, amaçlı örnekleme yöntemleri pek çok durumda, olgu ve olayların keşfedilmesinde ve açıklanmasında yararlı olmaktadır (Başaran, 2017, s. 49).

\subsection{Bulgular}

Zula oyunu, oyuncuların seçimine göre farklı haritalarda oynanabilmektedir. Oyunda bulunan haritalar ise; Çanakkale, Çin Bahçeleri, Düğün salonu, Favela, Gaziantep, Gemi, Hangar, İnşaat, İnternet Kafe, kereste fabrikası, Kıbrıs açıkları, Kuzey Irak, Metro,Nemrut, Otopark, Paris, Persapolis, Safranbolu, Trabzon Uzungöl, Üsküdar sokakları olmak üzere toplam 20 haritası mevcuttur.Oyun iç mekan yerleștirmelerine örnek olarak Hamidiye hazır su markasının otomatı Resim 1'de gösterilmiştir.

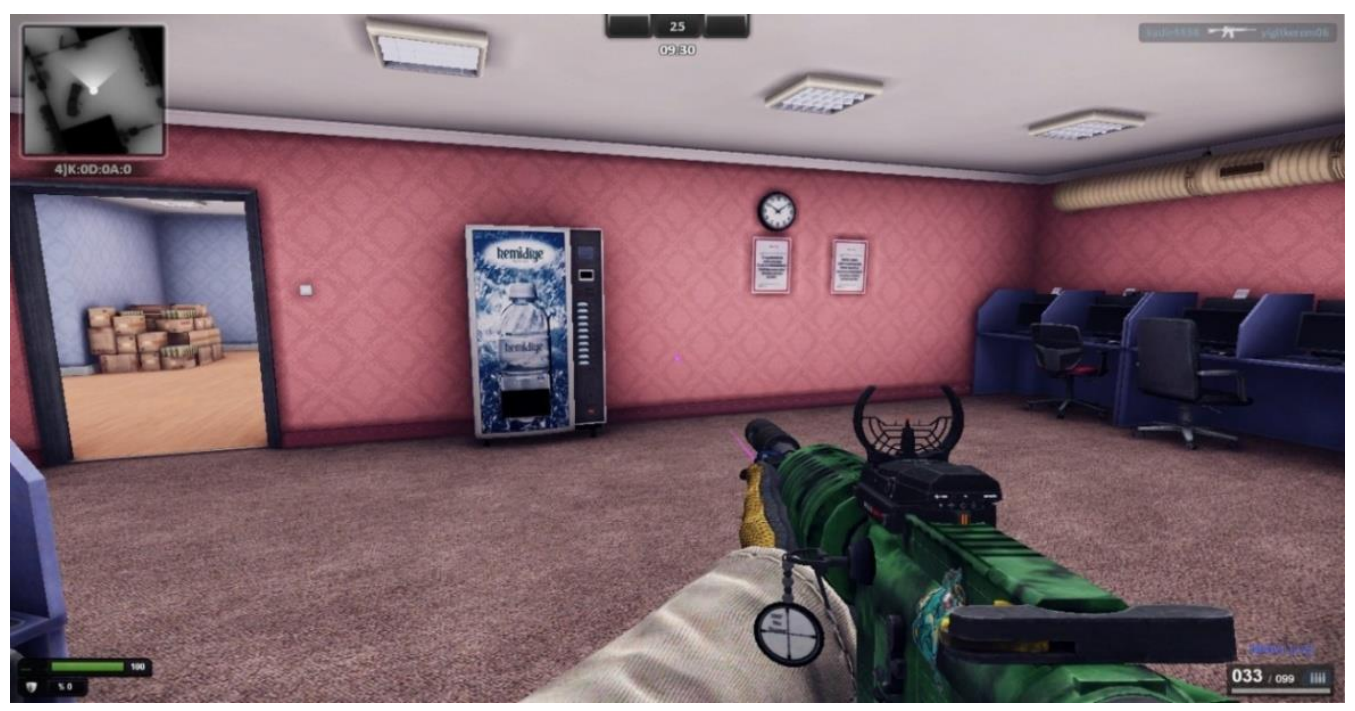

Resim 1: Hamidiye markasına ait otomat görseli 
Harita içerisinde dış mekan ürün yerleştirme örneği olarak Resim 2'de gösterilen büfe önünde Algida markasına ait dondurma dolabı ve yanında soğuk ve içecek dolabının içinde Cappy ve Coca-Cola markalarının ürünleri bulunmaktadır. Oyuncular bu içecekleri içememekte ve bunlarla herhangi bir eylem gerçekleştirememektedir.

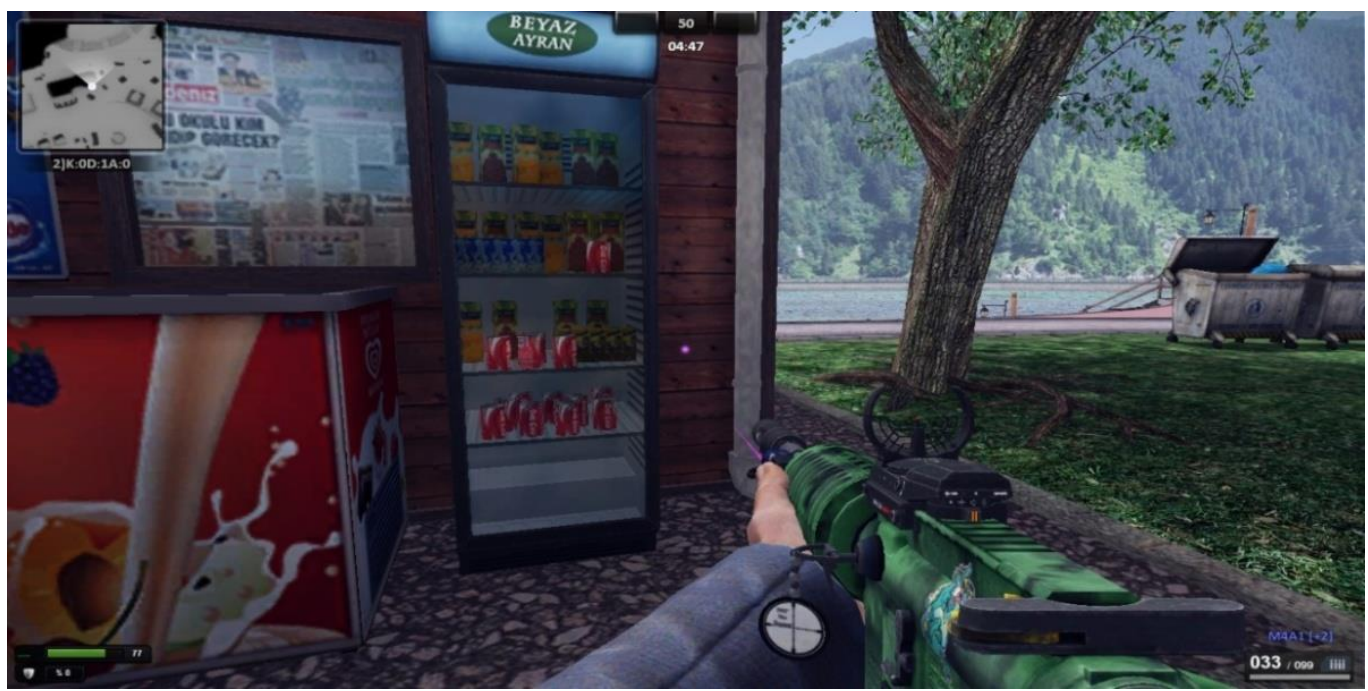

Resim 2: Yanyana yapılmış çoklu ürün yerleştirme

Tabela biçiminde oyun dış mekanında uygulanan Vodafone FreeZone görsel ürün yerleştirmesi aynı zamanda oyun içinde sanal para olarak kullanılan karşılığında oyun içi eşya satın alınmasını sağlayan Zula altını Resim 3’te gösterilmiștir.

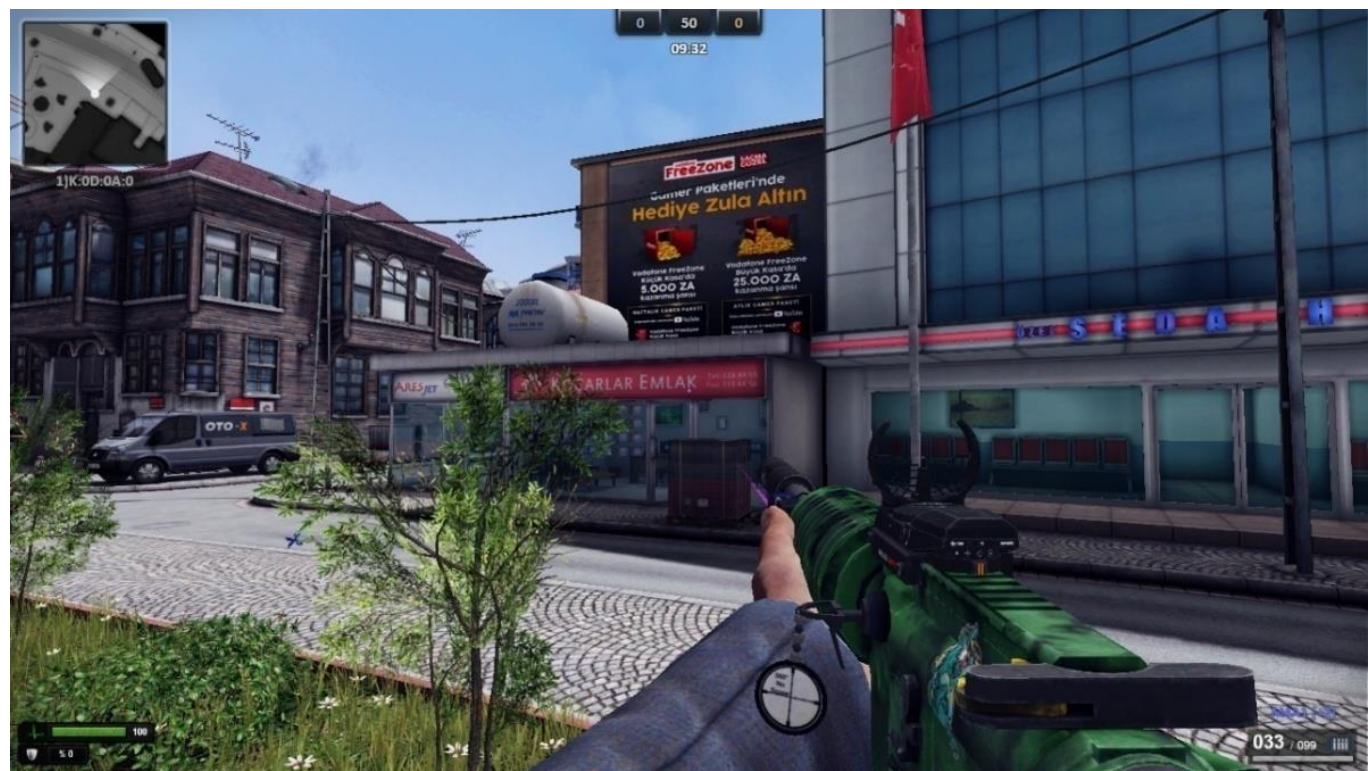

Resim 3: Vodafone markasına ait yapılmış reklam tabelası yerleştirmesi 
Oyunda dış mekan unsuru olarak yerleștirilmiş BMW markasına ait otomobil Resim 4'te gösterilmiştir. Oyuncular diğer taşıtlarda dahil olmak üzere bu araçları kullanamaktadır. Fakat bu araçları çatışmalar esnasında siper amaçlı kullanabilmektedirler.

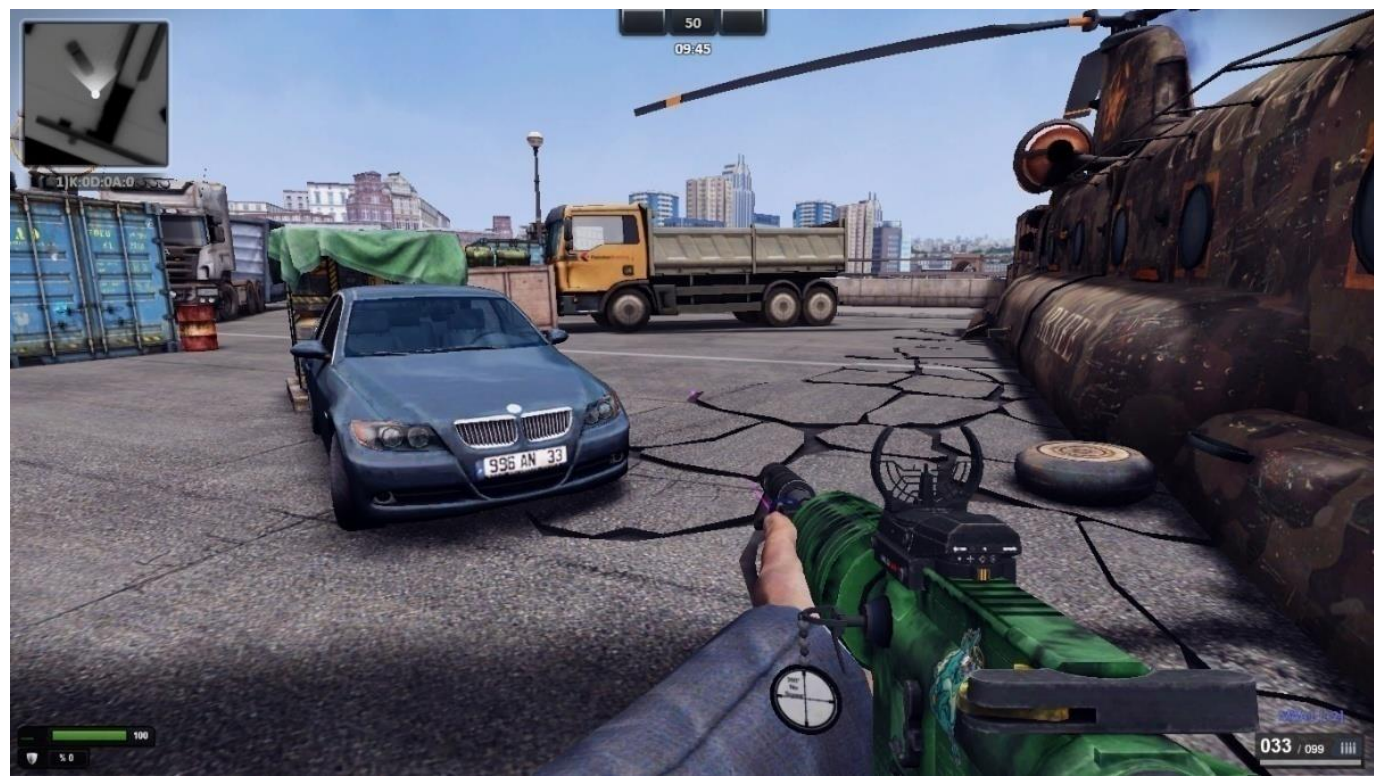

Resim 4: BMW markasına ait yerleștirmesi yapılmıș bir otomobil

Gerçek hayatta olduğu gibi reklam panosu șeklinde metro haritasında Vatan Bilgisayara ait ürün yerleştirmesi Resim 5’te gösterilmiştir.

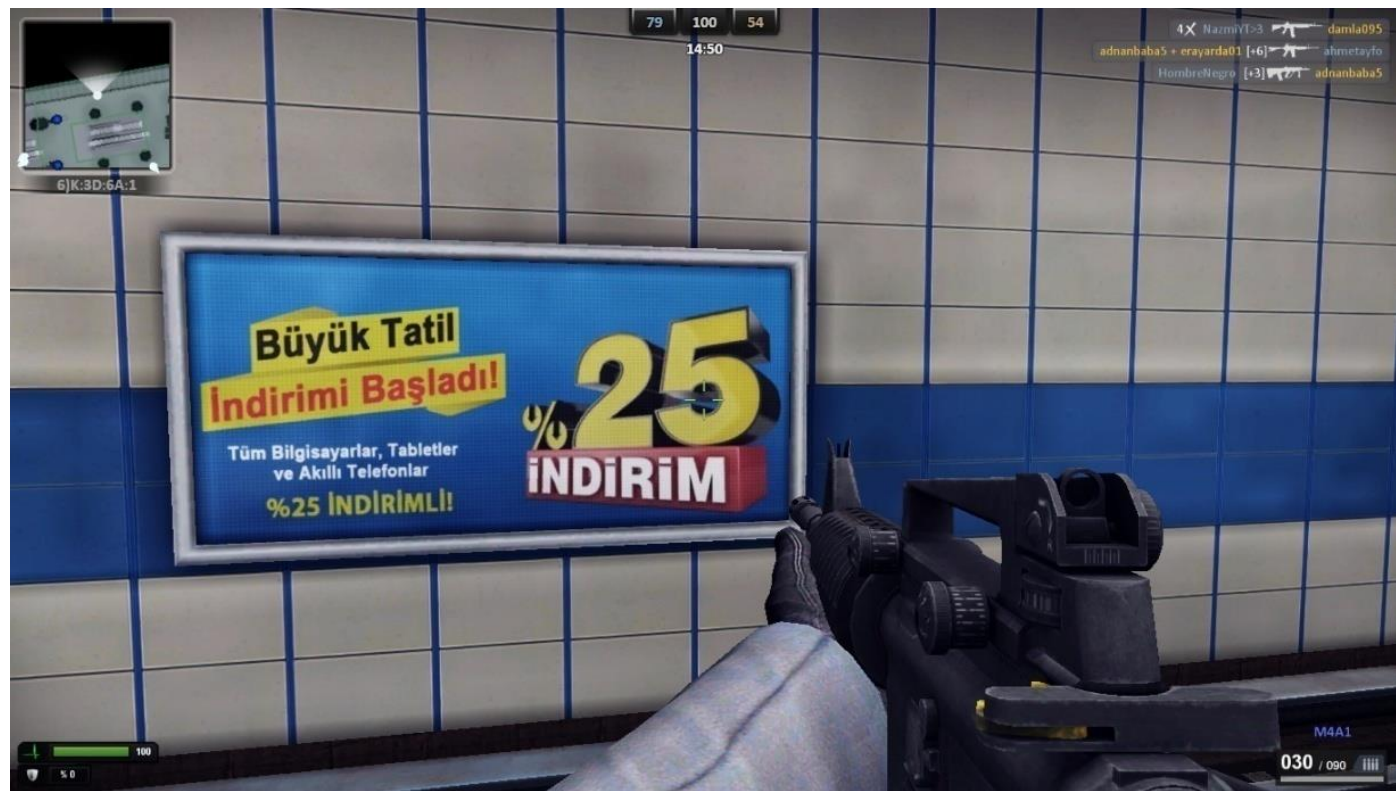

Resim 5: Vatan Bilgisayar markasına yönelik yapılmış reklam panosu biçiminde ürün yerleştirme 
Zula oyununda yer alan ürün yerleștirmelerinin sektörlere göre yüzde oranları ve s1klıkları Tablo 2'de belirtilmiştir.

Tablo 2: Oyun içerisinde uygulanan ürün yerleştirmelerin sıklık ve yüzdeleri

\begin{tabular}{|l|c|c|}
\hline Sektör & Frekans & Yüzde \% \\
\hline Gıda (İçecek) & 10 & 23,25 \\
\hline Otomotiv & 9 & 20,93 \\
\hline Gida (Yiyecek) & 4 & 9,30 \\
\hline Teknoloji & 3 & 6,97 \\
\hline Temizlik & 3 & 6,97 \\
\hline Telekomünikasyon & 2 & 4,65 \\
\hline Giyim & 2 & 4,65 \\
\hline Sinema ve Televizyon & 2 & 4,65 \\
\hline Yapı Malzemeleri & 2 & 4,65 \\
\hline Sivil Toplum Kuruluşları & 2 & 4,65 \\
\hline Siyasal Reklam & 1 & 2,32 \\
\hline Video Oyunları & 1 & 2,32 \\
\hline Kişisel Bakım & 1 & 2,32 \\
\hline Diğer & 1 & 2,32 \\
\hline Toplam & $\mathbf{4 3}$ & $\mathbf{1 0 0} \%$ \\
\hline
\end{tabular}

Oyun haritalarında bulunan ürün yerleştirmeleri sektörlere göre ele alındığında 13 farklı sektörün yer aldığı tespit edilmiştir. Bu sektörler arasında \%23,25 oran ile Gıda (İçecek) sektörü ilk sırada yer almaktadır. Ardından \%20,93 oran ile Otomotiv sektörü gelmektedir. Araç markalarının yanı sıra bu sektör içerisinde madeni yağ ve araç lastik markaları da bulunmaktadır. Bu sektörün arkasından \%9,30 oran ile Gıda (Yiyecek) sektörü gelmektedir. Bu sektörü oluşturan ürünler oyun esnasında tüketilebilecek cips ve kuruyemiş markalarıdır. Teknoloji ve Temizlik sektörlerine ait ürün yerleştirmeler \%6,97 eşit oranla bulunmakta ve teknoloji mağazaları alan yerleştirmesi olarak haritalar yer alırken bu firmaların billboardlarda vermiş oldukları reklamlar oyun içerisinde sergilenmektedir.

Teknoloji sektörüne yakın olarak \%4,65 oran ile Telekomünikasyon sektörüne ait firmaların ürün yerleştirmeleri tespit edilirken bu firmalarla yapılmış oyun içi iş birlikleri de 
oyun başlangıçta reklam olarak sunulduğu gözlemlenmiş̧tir. Sinema ve televizyon sektörüne ait yine $\% 4,65$ oran ile bir dizi ve bir filmin ürün yerleştirmesi yapılmıştır. Leyla ile Mecnun dizisinde yer alan Erdal Bakkal oyun haritasında açık bir şekilde oyun içi kullanılamayan sadece görsel amaçlı unsur olarak bulunurken, Semt Bizim Ev Kira filminin sloganı oyun içerisinde konutların duvarlarında yer aldığı tespit edilmiştir. Vizyona giriş tarihlerine göre ürün yerleştirme dışında oyun başlangıç ekranında Hababam Sınıfı Yeniden filminin reklamı ve fragmanı yer almaktadır.

Yap1 malzemeleri, Sivil Toplum Kuruluşları, Giyim, kategorilerinde ise \%4,65 eş oranı ile oyun haritalarında yerleştirilmiş ürünler, pano reklamlarının bulunduğu gözlemlenmiştir. Siyasal reklam kategorisinde ise oyun içi gözlemlerin Türkiye'de 31 Mart 2019 Yerel Seçimlerinin yapılacak olması sebebiyle konutların duvarlarında muhtar reklamlarına yer verildiği görülmüştür. Diğer kategorisinde yer alan yerleştirme ise oyun alanı olarak düğün salonu kullanılmasıdır.

En düşük sıklıkta görülen bir kategori ise \%2,32 oran ile Video Oyunlarıdır. Bir çok platformda oynanabilen ve yapımcısı Zula'nında yapımcısı olan Lokum Games tarafindan piyasa sürülen çevrimiçi oynanabilen bilardo oyunudur.Bununla birlikte aynı orana sahip Gillette markasına ait erkek kişisel bakım ürünü oyun içi yerleştirmelerin sonuncusu olarak tespit edilmiştir.

\section{SONUÇ VE ÖNERILER}

Bilgisayar oyunlarında ürün yerleştirmeye yönelik yapılan çalışmaların birçoğu (Zeren \& Paylar, 2016; Vashishta \& B.Royne, 2016; Latvasalo, 2017; Chaney, Hosany, Wu, Chen, \& Nguyen, 2018) reklamın hatırlanırlığı, satın almaya etkileri, uzun ve kısa süreli hafızalardaki yeri, marka bilinirliği, marka farkındalığı gibi konuları ele almaktadır. Yapılan bu araştırma, daha önce ele alınmamış olan MMOFPS türünde olması ve oyun içerisindeki yerleştirmelerin sektörel dağılımlarının ortaya çıkarılmış olmasıyla diğer çalışmalardan farklılığını ortaya koymaktadır. Daha önce yapılmış çalışmalarda ağırlıklı olarak araba yarışı, futbol, basketbol gibi spor oyunları araştırma konusu olmuştur. Tablo 1'e bakıldığında 9 farklı çok oyunculu çevrimiçi oyun türünün olduğu görülmektedir. Çavdar (2020) tarafindan yapılan spor oyunlarında ürün yerleştirme çalışmasında en fazla sigortacılık - finans ardından otomotiv ve teknolojien az ise video oyunları, mutfak aletleri, yapı malzemeleri, emlak sektörlerindekiürün yerleştirmeler bulunmuştur. Bu araştırmada ise en fazla sırasıyla içecek, 
otomotiv, yiyecek en az ise video oyunları, siyasal reklam ve kişisel bakım yer almaktadır. Buradan anlaşılacağı üzere yapılan ürün yerleştirmeler oyunun türüne göre değişiklik göstermektedir.

Oyunun hedef kitlesine göre yapılan ürün yerleştirmeler oyuncuların dikkatini çekerek ürünlere karşı olan ilgilerini artırabilir.Oyun mekanı seçimi açısından turistik ve görülmeye değer yerlerin haritalandırılması ve bu haritalara uygun ürünlerin yerleştirilmesi titizlikle yapılmalıdır. Oyuna kayıt esnasında kullanıcılarının okuyup kabul ettiği sözleşmenin 3. maddesinde "sitedeki oyunların oyuncuların yaş gruplarına uygunluğunu denetlemek ve bu hususta karar vermek yetkisi oyunculara aittir. Kullanıcının yaşının yasal rüşt sınırının altında olması halinde yasal temsilcilerine oynamayı tercih ettiği oyunun kendi yaş grubu için uygunluğunu sorması ve onun onayı ile ilgili oyunu oynamast veya oynamaya devam etmesi önerilmektedir."ibaresi yer almaktadır. Fakat oyuna üye olduktan sonra 15 yaşında büyük olunup olmadığının sorulduğu tespit edilmiştir. Aynı zamanda oyunun müsabaka sitesinde yer alan bilgilere göre Zula oynayabilmek ve resmi turnuvalarına katılabilmek için oyuncuların 15 yaşını doldurmuş olmaları, ödülden faydalanabilmeleri için ise yazılı veli izni olmaları veya 18 yaşını doldurmuş olmaları gerekmekte olduğunu belirten bir madde geçmektedir. Buradan da anlaşılacağı üzere oyunda herhangi bir yaş sınırlaması olmadığı açıkça anlaşılmaktadır. Bu doğrultuda yapılabilecek ürün yerleştirmelerinin her yaş grubunun istek ve ihtiyaçları göz önüne alarak değerlendirilmelidir. Ebeveynler oyunları çocuklarıyla birlikte oynayacağı düşünüldüğünde ailelerin beklentilerine yönelik ürün yerleştirmeleri yapılması faydalı olacaktır. Oyunda bir diğer önemli husus ise cinsiyet ayrımı yapılmamasıdır. Oyuna kayıt ekranında kullanıcılara cinsiyeti sorulmamakta böylece yapılacak ürün yerleştirmelerinin her cinsiyete uygun seçilmesi gerekmektedir. Oyunda sadece ulusal oyuncular değil yabancı uyruklu oyuncularında kendi dillerinde oyuna dahil oldukları düşünüldüğünde uluslararası pazara girme öncesi yapılacak hazırlıklar arasında da ürün yerleştirmelerinin tüketicilerde bir alg1 oluşmasını sağlamada da önemli rolü olacağı düşünülmektedir. Dijital oyun dünyasının, internetin ve kişisel bilgisayarların her geçen gün giderek yaygınlaştığı ortamda firmaların rekabet süreçleri içerisinde bu alanı yakından takip etmeleri yararlarına olacaktır. 


\section{EXTENDED ABSTRACT}

The competitive market of our time causes the target audience to increase their frequency of receiving in the advertising messages and to be equipped with the advertising contents of every corner of our lives. In this period, where brands have exerted great efforts to discover new ways of reaching and influencing consumers, product placement stands out as an effective marketing communication tool. With the success of the films, cinema has become one of the most important mass media in human history. The cinema attracted the attention of its advertisers with the excessive demand of the audience. However, it is possible to see the first product placement applications in the cinema, including all mass media, in all areas of our lives. The uninterrupted progress of the IT sector creates new channels for advertisers day by day. The use of video games for advertising is from ancient times. It is seen 80 years ago that Budweiser and Marlboro brands were placed in video games such as Tapper and Pole Position. The growing interest in video games worldwide has also increased the interest of brands to use video games as a way to approach consumers effectively and indirectly. Video games do not only address the young generation. It is known that people from many age groups are interested in games since the game culture and history goes back to very old times. In terms of variety and access, games have become a part of our lives with the ability to play independently from the place with handheld consoles, tablets and smartphones.

Product placement in video games is done in three different ways. The first method is the method by which the brand or product appears on the screen, that is, by visual product placement. The second is the audio product placement where the audio content refers to the brand or product. The third is the placement of the area where the brand or product is fully included in the field of the game. These installations are exactly the same as the application of product placement in the cinema and television industry. Due to the nature of video games, unlike video games, there are placements made through the interaction between the player and the brand. The player uses the product as an object in the game and gives an additional dimension to the placement of the product with the interaction that occurs. Thanks to this interaction, the awareness of the player towards the brand increases.

The content analysis was used because the purpose of the research was to identify the product placements in online video games. Content analysis, which is a qualitative research method, is a systematic neutral and numerical analysis to measure the variables in a text. The 
study was carried out using a scanning model suitable for the research purpose. The scanning model aims to describe an existing situation as it is without changing it. In this framework, the first Turkish-made and free multiplayer was selected with the sampling method used for ZULA purposes and was regularly observed in-game between January 2019 and April 2019, and the product placements of the brands were divided into groups. The purpose of the purposeful sampling is to address situations that contain rich information to clarify the problems to be addressed in the research. In this sense, purposeful sampling methods are useful in many cases in discovering and explaining facts and events.

When product placements in game maps are analyzed by sectors, it is determined that there are 13 different sectors. The Drink sector ranks first among these sectors with a rate of $23.25 \%$. Automotive sector is followed by $20.93 \%$. In addition to vehicle brands, there are also mineral oil and vehicle tire brands in this sector. The Food sector comes after this sector with a rate of $9.30 \%$. The products that make up this sector are chips and nuts brands that can be consumed during the game. Product placements belonging to the Technology and Cleaning sectors are found with an equal ratio of $6.97 \%$ and while the maps are located as technology stores, the advertisements given by these companies on the billboards are displayed in the game. While the product placements of the companies belonging to the Telecommunication sector with $4.65 \%$ close to the technology sector were determined, it was observed that ingame collaborations with these companies were also offered as advertisements at the beginning of the game. The product placement of a series and a movie belonging to the Cinema and Television sector, again with a rate of $4.65 \%$. It has been observed that there are products placed on game maps with $4.65 \%$ equivalent ratio in building materials, nongovernmental organizations, clothing, and board ads. In the category of political advertising on the walls of the houses due to be held in Turkey in-game observations of March 31, 2019 local elections were seen as giving place to the headman ads. Placement in the other category is the use of a wedding hall as a playground. The category with the lowest frequency is Video Games with a rate of $2.32 \%$. It is an online game that can be played on many platforms and released by Lokum Games, its producer Zula. However, the male personal care product of Gillette brand with the same ratio has been identified as the last in-game placement.

According to the research result, it can be said that product placement in online multiplayer games covers a wide variety of sectors. Product placements made according to the 
target audience of the game can attract the attention of the players and increase their interest in the products. Considering that they are included in the game in their own language, not only national players but also foreign national players, it is thought that product placement will also play an important role in creating a perception among consumers among the preparations to be made before entering the international market. In an environment where the digital game world, internet and personal computers are becoming more and more widespread, it will be beneficial for the companies to follow this area closely during the competition processes.

\section{KAYNAKÇA}

Akbulut, H. (2009). Gelenekselden dijitale, mekândan uzama oyun kültürü. M. Binark, G. Bayraktutan-Sütcü, \& I. B. Fidaner (Dü) içinde, Dijital oyun rehberi (s. 25-81). İstanbul: Kalkedeon.

Akıncı, S., \& Çakır, V. (2014). Para-sosyal ilişki teorisi perspektifinden ürün yerleştirme etkililiği. INIF E-dergi, 2 (2), 210-228.

Akkan, E. (2006). Pazarlama iletişiminde ürün yerleştirme ve üniversite ögrrencilerinin ürün yerleştirmeye ilişkin tutumlarına yönelik bir araştırma. (Yayımlanmamış yüksek lisans tezi), Anadolu Üniversitesi, Sosyal Bilimler Enstitüsü, Eskişehir.

Altıntaş, D. (2009). Pazarlama iletişiminde ürün yerleştirmenin hatırlatıcı etkisi. (Yayımlanmamış yüksek lisans tezi), Atatürk Üniversitesi, Sosyal Bilimler Enstitüsü, Erzurum.

Argan, M., Velioğlu, M. N., \& Argan, M. T. (2007). Marka yerleştirme stratejilerinin hatırlama üzerine etkisi: 'GORA' filmi üzerine araştırma. Elektronik Sosyal Bilimler Dergisi , 6 (19), 159-178.

Arık, İ. A. (1992). Psikolojide bilimsel yöntem. İstanbul: İstanbul Üniversitesi Basımevi.

Balasubramanian, S. K. (1994). Beyond advertising and publicity: hybrid messages and public policy issues. Journal of Advertising , 23 (4), 29-46.

Başaran, Y. K. (2017). Sosyal bilimlerde örnekleme kuramı. Akademik Sosyal Araştırmalar Dergisi , 5 (47), 480-495. 
Binark, M., \& Bayraktutan-Sütçü, G. (2008). Kültür endüstrisi ürünü olarak dijital oyun. İstanbul: Kalkedon.

Boluda, I. K., Pardo, E., \& Suemanotham, T. (2011). Product placement in video games as a marketing strategy: an attempt to analysis in Disney company. Working papers $=$ Documentos de trabajo: Serie EC-(Instituto Valenciano de Investigaciones Económicas) , 4 (1), 1-33.

Chan, F. F., Lowe, B., \& Petrovici, D. (2016). Processing of product placements and brand persuasiveness. Marketing Intelligence \& Planning , 355.

Chaney, I., Hosany, S., Wu, M.-S. S., Chen, C.-H. S., \& Nguyen, B. (2018). Size does matter: effects of in-game advertising stimuli on brand recall and brand recognition. Computers in Human Behavior, 86, 311-318.

Chen, H., \& Wang, Y. (2016). Product placement in top-grossing hollywood movies: 20012012. Journal of Promotion Management, 22 (6), 835-582.

Çavdar, C. (2020). Video oyunlarındaki ürün yerleştirme uygulamaları: Spor oyunlarına yönelik bir içerik analizi. (Yayımlanmamış yüksek lisans tezi), Ege Üniversitesi, Sosyal Bilimler Enstitüsü, İzmir.

Eagle, L., \& Dahl, S. (2018). Product placement in old and new media: examining the evidence for concern. Journal of Business Ethics , 147 (3), 605-618.

Gerçek, İ. S., \& Tanyıldızı, N. İ. (2012). Marka farkındalığı yaratmada türk sinemasında ürün yerleştirme uygulamaları: Anadolu Kartalları, Kolpaçino Bomba ve Aşk Tesadüfleri Sever filmleri üzerinde bir araştırma. The Journal of Academic Social Science Studies, 5 (8), 1095-1109.

Gürcan, A., Özhan, S., \& Uslu, R. (2008). Dijital oyunlar ve çocuklar üzerindeki etkileri. Başbakanlık Aile ve Sosyal Araştırmalar Genel Müdürlüğü , 1-50.

Huizinga, J. (1995). Homo Ludens: Oyunun toplumsal işlevleri üzerine bir deneme. (M. A. Kılıçbay, Çev.) İstanbul: Ayrıntı Yayınları.

Kanca, E. (2011). Oyunun antropolojisi. Ankara: Genesis Kitap. 
Korkusuz, M. E., \& Karamete, A. (2013). Eğitsel oyun geliştirme modelleri. Necatibey Eğitim Fakültesi Elektronik Fen ve Matematik Eğitimi Dergisi (EFMED) , 7 (2), 78-109.

Latvasalo, P. (2017). Brands into BitsGame advertising integrations' effect on brand awareness. Vaasa: Department of Marketing, Hanken School of Economics, Master Thesis.

Liang, A. R.-D., Hsiao, T.-Y., \& Cheng, C.-H. (2015). The effects of product placement and television drama types on the consumer responses of college students. Asia Pacific Journal of Tourism Research , 20 (11), 1212-1233.

Majhi, S. S. (2011, May1s 23). Dragonblogger. Nisan 30, 2019 tarihinde https://www.dragonblogger.com/16-types-massively-multiplayer-mmo-online-games/ adresinden alınd 1

Martí-Parreñoa, J., Bermejo-Berros, J., \& Aldás-Manzano, J. (2017). Product placement in video games: The effect of brand familiarity and repetition on consumers' memory. Journal of Interactive Marketing (38), 55-63.

Mazıcı, E. T., Ateş, N. B., \& Yıldırım, A. (2017). Televizyon programlarında ürün yerleştirme:“Survivor All Star” örneği. Selçuk İletişim , 9 (4), 238-257.

Nakıboğlu, B., \& Serin, N. (2016). Ürün yerleştirme uygulamalarının tüketici satın alma niyeti ile ilişkisi hakkında pilot bir araştırma. Niğde Üniversitesi İktisadi ve İdari Bilimler Fakültesi Dergisi , 9 (2), 135-151.

Neer, K. (2003, Haziran 4). HowStuffWorks. Nisan 2, 2019 tarihinde https://money.howstuffworks.com/product-placement.htm adresinden alınd1

Neuman, W. (2007). Toplumsal araştırma yöntemleri: Nitel ve nicel yaklaşımlar (Cilt 1). (S. Özge, Çev.) İstanbul: Yayınodası.

Ömerbaş, Ç. (2016, Ağustos 10). Manifold. Nisan 15, 2019 tarihinde https://manifold.press/oyun-kulturunun-neredeyse-kronolojik-gelisimi adresinden alınd 1

Özgen, C., Yüce, A., \& Katırc1, H. (2018). Sporun reklamlardaki gücü: Türk televizyon kanallarında yayınlanan reklamlarda spor imgesi. Sport Sciences , 13 (2), 10-22. 
Rubin, A., \& Babbie, E. (2014). Research methods for social work. CA, Brooks: Belmont.

Terek, Ü., \& Batı, U. (2011). Dijital oyunlar. İstanbul: Derin.

Tezel, Y. (2016). Bilgisayar oyunları tarihi. İstanbul: Sokak Kitapları Yayınları.

T1ğglı, M. (2004). Bir aktör olarak markalar: ürün yerleştirme. İstanbul: Türkmen Kitabevi.

Topal, A. (2016). Sanal karakterin gerçek gündemi: Çevrimiçi oyunlarda metin tabanlı iletişim ve "World of Warcraft" örneği. (Yayımlanmamış yüksek lisans tezi), Kocaeli Üniversitesi, Sosyal Bilimler Enstitüsü, Kocaeli.

Usta, A. (2009, Aralık). Skylife. Nisan 10, 2019 tarihinde https://www.skylife.com/tr/200912/dijital-cagin-oyunlari adresinden alınd1

Vaerenbergh, Y. V., Sompel, D. V., Loock, N. V., \& Vermeir, I. (2011). The impact of brand name placement in song lyrics on brand attitudes: Does the attitude toward the artist matter? In Advances in Advertising Research (Vol. 2) , 21-33.

Vashishta, D., \& B.Royne, M. (2016). Advergame speed influence and brand recall: The moderating effects of brand placement strength and gamers' persuasion knowledge. Computers in Human Behavior, 63, 162-169.

Yengin, D. (2012). Dijital oyunlarda şiddet. İstanbul: Beta.

Zeren, D., \& Paylar, Ö. Z. (2016). Bilgisayar oyunlarında ürün yerleştirme: Pro Evolution Soccer (Pes) 2015 örneği. AJIT-e: Online Academic Journal of Information Technology, 52-68.

Zeren, D., \& Paylar, Ö. Z. (2014). Ürün yerleştirme: Milenyum itibariyle Türk sinemasindaki durum. Adana: Karahan. 